\title{
"Cardiac profile in Type 2 Diabetes Mellitus patients with normal resting ECG with special reference to Echocardiography and TMT"
}

\author{
${ }^{1}$ Dr.Seema mahant, ${ }^{2}$ Dr. M.K.Jain, ${ }^{3}$ Dr.Julie Abrahim \\ ( Professor,Dept. of Medicine,PCMS \& RC,Bhopal.M.P.) \\ (Prof.\&Head,Dept. of Medicine,S.S.Medical collage,Rewa,M.P.) \\ (Resident, Dept. of Medicine,S.S.Medical collage,Rewa,M.P)
}

\begin{abstract}
AIMS AND OBJECTIVES- This study was undertaken to evaluate the extent of cardiac dysfunction by echocardiography assessment and TMT performance in patients of NIDDM with normal resting ECG.

Methodology- Fifty type-II diabetic patients were evaluated with normal resting ECG irrespective of age and sex admitted in the wards of Department of Medicine was selected for the study. The diagnosis of diabetes was made according to WHO criteria -Symptoms of diabetes plus random blood glucose concentration $\geq 11.1$ $\mathrm{mmol} / \mathrm{L}(200 \mathrm{mg} / \mathrm{dl})$.Or Fasting plasma glucose $\geq 7.0 \mathrm{mmol} / \mathrm{L}(126 \mathrm{mg} / \mathrm{dl})$.Or Two hour plasma glucose $\geq 11.1$ $\mathrm{mmol} / \mathrm{L}(200 \mathrm{mg} / \mathrm{dl})$ during an oral glucose tolerance test. All subjects were subjected to routine and special investigations which included 12 lead ECG, TMT, and echocardiographic assessment.

Results: Out of the 50 patients, 33 patients (66\%) had abnormal echocardiographic findings. $50 \%$ of the patients (25 out of 50 patients.) had diastolic dysfunction while 34\% (17 out of 50 patients) had left ventricular hypertrophy. Diastolic dysfunction was highest in patients $>60$ years of age (90.91\%) compared to $47.8 \%$ and $25 \%$ in the age group 46-60 years and 30-45 years respectively. The incidence of diastolic dysfunction was the highest (100\%) in patients with diabetes duration $>10$ years. $40 \%$ of the patients had HbAlC level $>10 \%$ of which $65 \%$ had diastolic dysfunction. TMT was positive in 05 out of 50 patients $(10 \%)$. Out of the 17 females, two (11.76\%) had positive TMT compared to three (9.09\%) positive TMT out of 33 males.

Conclusion: The results of this study suggest that the incidence of left ventricular diastolic dysfunction is higher in NIDDM patients who are free of clinically detectable heart disease. It was found that the incidence of diastolic dysfunction had a strong correlation with the age, duration of diabetes, HbAlC level and diabetic complications. Stress test positivity in type-2 diabetic patients didn't show any correlation with sex, age, addiction, duration of diabetes, and systolic blood pressure. In the present study, it was also found that asymptomatic coronary heart disease occurs in type 2 diabetic patients. Hence it is advisable to screen these patients by TMT and confirm/rule out coronary heart disease by coronary angiography.
\end{abstract}

Key wards-Normal resting ECG, Type II DM and Cardiac Evaluation.

Submitted date 10 June 2013

Accepted Date: 15 June 2013

\section{Introduction}

The American Diabetes Association has designated diabetes as cardiovascular disease equivalent. The increased risk of morbidity and mortality due to cardiovascular disease is associated with abnormalities in glucose metabolism1,11. Both ischemic heart disease and a true diabetic myocardial disease developing in long standing diabetic subjects may be responsible for heart failure in diabetics1,4. The Framingham study had shown that diabetic men had a 2.4 fold increased incidence of heart failure and rising to 5.1 fold increased incidence in diabetic women 1,5. Although systolic and diastolic functions of the heart are impaired in diabetes, many studies have shown that LV diastolic abnormalities are the most common and may in fact precede the development of systolic abnormality2,3,6. Detection of such asymptomatic LV dysfunction is of importance so that early treatment with ACE Inhibitors may help the patients.7, 10

Keeping this in view, it was thought to study patients of type 2 diabetes mellitus for analysis of cardiac function noninvasively by measuring LVEF, IVRT and left ventricular filling patterns (transmitral- flow velocity pattern) obtained by echocardiography and Doppler study and asymptomatic coronary heart disease by tread mill test $.8,9$

\section{Materials and Methods-}

The present study titled "Cardiac Profile in Type-2 Diabetes Mellitus Patients with Normal Resting ECG with Special Reference to Echocardiography and TMT" was carried out in patients attending the MOPD 
and those admitted in Department of Medicine S.S. Medical College and Associated S.G.M. Hospital, Rewa (M.P.) with following inclusion criteria-

A random sample of 50 patients of type-II diabetes mellitus with normal resting ECG irrespective of age and sex admitted in the wards of Department of Medicine were selected for the study.

The diagnosis of diabetes was made according to WHO criteria which include:- Symptoms of diabetes plus random blood glucose concentration $\geq 11.1 \mathrm{mmol} / \mathrm{L}(200 \mathrm{mg} / \mathrm{dl})$. Or Fasting plasma glucose $\geq 7.0 \mathrm{mmol} / \mathrm{L}$ (126 mg/dl). Or Two hour plasma glucose $\geq 11.1 \mathrm{mmol} / \mathrm{L}(200 \mathrm{mg} / \mathrm{dl})$ during an oral glucose tolerance test.

\section{METHODS:}

1. Detailed history of the subjects with special reference to symptoms pertaining to diabetes mellitus and coronary risk factors (addiction, hypertension, dyslipidemia, family history of coronary artery disease etc) were recorded.

2. Clinical examination emphasized measurement of height, weight, BMI and blood pressure. Height was measured in meters and weight recorded in kilograms using a calibrated weighing machine. At least two recordings of blood pressure at 5 minutes interval as per WHO Guidelines were taken.

3. All subjects were subjected to routine and special investigations which included.

(a) Routine blood investigations - $\mathrm{Hb} \%$, TLC, DLC.

(b) Blood biochemistry -blood sugar, blood urea., s.creatinine, s.cholesterol,HbA1C

(c) Urine examination.

(d) Ophthalmological evaluation

(e) X-ray chest PA view.

(f) Standard 12 lead electrocardiogram.

(g) Treadmill stress testing.

(h) Echocardiography including pulse wave Doppler

Patients were evaluated by 12 lead ECG performed with proper standardization and those with an abnormal ECG were excluded from the study.

Observations: In this study, Echocardiography and TMT were done in 50 type-2 diabetes mellitus patients with normal resting ECG. After analyzing the data following observations were made.

Table - 1

Echocardiographic Evaluation in the Study Group

\begin{tabular}{|l|c|c|}
\hline & Number of Cases $(\mathbf{n = 5 0})$ & \% of cases \\
\hline Normal & 17 & $34 \%$ \\
\hline Abnormal & 33 & $66 \%$ \\
\hline 1. Diastolic Dysfunction & 25 & $50 \%$ \\
\hline 2. LVH & 17 & $34 \%$ \\
\hline
\end{tabular}

$\mathrm{Z}=-2.42$, Not significant

The above table shows that out of the 50 patients, 33 patients $(66 \%)$ had abnormal echocardiographic findings. $50 \%$ of the patients ( 25 out of 50 patients.) had diastolic dysfunction while $34 \%$ (17 out of 50 patients) had left ventricular hypertrophy.

Table - 2

TMT Evaluation in the Study Group

\begin{tabular}{|l|c|c|c|}
\hline \multirow{2}{*}{ Sex } & \multirow{2}{*}{\begin{tabular}{c} 
Number of Patients \\
\multirow{2}{*}{}
\end{tabular}} & & \multicolumn{2}{c|}{ Tread Mill Test } \\
\cline { 2 - 4 } & $17(34 \%)$ & $02(11.76 \%)$ & Negative (\%) \\
\hline Female & $33(66 \%)$ & $03(09.09 \%)$ & $15(88.24 \%)$ \\
\hline Male & $\mathbf{5 0}$ & $\mathbf{0 5}$ & $30(90.91 \%)$ \\
\hline Total & & $\mathbf{4 5}$ \\
\hline
\end{tabular}

$$
=0.08, \mathrm{p}=0.76 \text {, Not Significant }
$$

The above table shows that most of the cases were males $(66 \%)$ but positive stress test were more in females $(11.76 \%)$ compared to that in males(9.09\%). 
Table -3

Correlation Between 2D Echocardiography and TMT findings

\begin{tabular}{|c|c|c|}
\hline \multirow[t]{2}{*}{ Echocardiographic Findings } & \multicolumn{2}{|l|}{ Tread mill test } \\
\hline & Positive & Negative \\
\hline Diastolic dysfunction Present $\quad(n=25)$ & 00 & $25(100 \%)$ \\
\hline LVH $(n=17)$ & $03(17.63 \%)$ & $14(82.35 \%)$ \\
\hline Normal ECHO( $n=17)$ & $02(11.76 \%)$ & $15(88.24 \%)$ \\
\hline
\end{tabular}

The above table shows that out of the 25 patients with diastolic dysfunction no one had positive TMT. Out of the 17 patients with LVH, 3 patients had positive TMT while only 2 patients with normal echocardiographic finding had positive TMT. These findings were statistically insignificant.

\section{Conclusion-}

It can be concluded that the incidence of left ventricular diastolic dysfunction is higher in type 2 diabetes mellitus patients who are free of clinically detectable heart disease. In the present study, it was found that the incidence of diastolic dysfunction had a strong correlation with the age of the patient and duration of diabetes .In the present series the incidence was more in patients with diabetic complications, those with HbA1C level $>10 \%$, in known diabetic hypertensive. TMT was positive in $10 \%$ of the patients. Incidence of stress test positivity was more in the upper class patients, those who led a sedentary life style, those with HbA1C level $>10 \%$, those with diabetic complications and those with BMI more than $30 \mathrm{~kg} / \mathrm{m}^{2}$. This study emphasizes the need of evaluation of type 2 diabetic patients for early detection of diastolic dysfunction as a part of the preventive management in diabetics even if the resting ECG is normal. In the present study, it was also found that asymptomatic coronary heart disease occurs in type 2 diabetic patients. Hence it is advisable to screen these patients by TMT and confirm/rule out coronary heart disease by coronary angiography.

\section{References}

[1]. Bauters C, Lamblin N, McFadden EP, Van Bell E, Millaire A, DeGroote P: Influence of diabetes mellitus on heart failure risk and outcome. Cardiovasc Diabetol 2:1-16, 2003

[2]. Annonu AK, Fattah AA, Mokhtar MS, Ghareeb S, Elhendy A. Left ventricular systolic and diastolic functional abnormalities in asymptomatic patients with non insulin dependent diabetes mellitus. J Am Soc Echocardiogr. 2001; 14:885-91.

[3]. Falcone C, Nespoli L, Geroldi D, Gazzauruso C, Buzzi MP, Auguardo C, Tavazzi L, Schwartz PJ. Silent myocardial ischemia in diabetic and non diabetic patients with coronary artery disease; Int J Card, 2003; 90, 219-227.

[4]. Gani Bajraktari, Spiro, Nehat Rexhepaj et al. Non insulin dependent diabetes as an independent predictor of asymptomatic left ventricular diastolic dysfunction. Croat Med J 2005; 46(2):225-231.

[5]. Gregg C Fonarow, Preethi Srikanthan Diabetic Cardiomyopathy. Endocrinol. Metab Clin N Am. 35 (2006) 575-599

[6]. Roberto M. Saraiva, Dario M. Duarte Monica, PC Duarte et al. Tissue Doppler imaging identifies asymptomatic normotensive diabetics with diastolic dysfunction and reduced exercise tolerances. Echocardiograph, Vol 22;Aug 2005: page 561-570.

[7]. S.M. Sohail Ashraf, Fasia Basir. Association of hypertension and diastolic dysfunction with type 2 diabetes mellitus. Pak. J. Med. Sci. 2007 Vol 23: No. 3

[8]. Schannwell CM, Schneppenheim M, Perings S, et al; Left ventricular diastolic dysfunction as an early manifestation of diabetic cardiomyopathy; Cardiology 2002;98:33-9

[9]. Struthers AD, Morris AD. Screening for and treating left ventricular abnormalities in diabetes mellitus : a new way of reducing cardiac deaths. Lancet 2002; 359:1430-32.

[10]. Wackers FJ, Young LH, Inzucchi SE, Chyun DA, Davey JA, Barret EJ, TaiVefer R, Wittlin SD, Heller GV, Filipchuk N, Engle S, Ratner RE, Iskandrian AE. Detection of silent myocardial ischemia in asymptomatic diabetic subjects, the DIAD study. Diabetes care; 2004: 27:1954-1961.

[11]. Wild S, Roglic G, Green A etal; Global prevalence of diabetes: estimates for the year 2000 and projection for 2030. Diabetes care 2004; 27:1047-53. 